\title{
Journal of Medical Microbiology and Infectious Diseases
}

\section{Ghana is Free from the Guinea Worm after a 33-Year Eradication Program}

\author{
Langbong Bimi $^{([)}$, Francis Anto ${ }^{2}\left(\mathbb{C}\right.$, Ato Kwamena Tetteh $^{3 *([)}$ \\ ${ }^{1}$ Department of Animal Biology \& Conservation Science, University of Ghana, Post Box LG. 67, Legon-Accra, Ghana; \\ ${ }^{2}$ School of Public Health, College of Health Sciences, University of Ghana, Legon-Accra, Ghana; ${ }^{3}$ School of Public \\ Health, Georgia State University, Atlanta, Georgia 30301
}

\begin{tabular}{l}
\hline A R T I C L E I N F O \\
\hline Review Article \\
Keywords: Dracunculiasis, Ghana, \\
Carter Center, Drinking water, \\
Eradication
\end{tabular}

Received: 13 May. 2021

Received in revised form: 03 Jun. 2021

Accepted: 14 Jun. 2021

DOI: $10.52547 /$ JoMMID.9.2.55

*Correspondence
Email: atetteh3@ student.gsu.edu
Tel: +14043108632
Fax:

(C) The Author(s)

(cC)

A B S T R A C T

For several generations, people from some parts of Ghana have suffered in the hands of a yard-long "spaghetti-thin" worm, known as Dracunculus medinensis, which infects humans and leads to a disease known as Dracunculiasis, literally meaning "afflictions with little dragons." The disease, also commonly known as Guinea Worm Disease, Dracuntiasis, or Dracunculosis, is a 3000-year-old known parasitic infection that rarely made headlines before the mid-1980s. Guinea Worm Disease, a plague so ancient that it is believed to be the "fiery serpent torturing the Israelites in the desert," as described in the Old Testament. This paper reviews local and global efforts and strategies at eradicating the disease in Ghana and further diagnoses the problems that hindered the early realization of the desired results of these strategies. This article did not evaluate Ghana's performance in the program. It is equally arduous to unearth all the reasons contributing to the somewhat uneasy road to eradication over three decades of efforts. This review analyzes time-trends, program documents, technical and non-technical reports, and research documents that reveal that Ghana's program ended a decade of disappointing stagnation following the disruptive ethnic conflicts in the early 1990s in its most disease-endemic areas. Despite substantial reductions in the number of guinea worm cases during the mid-1980s, efforts to break the transmission chain in Ghana remained a daunting task. The efforts required continued international and political commitment, active surveillance, strengthening of interventions, and honesty of documenters at all levels.

\section{INTRODUCTION}

Guinea Worm Disease, also known as Dracunculiasis, is caused by the adult female Dracunculus medinensis, which egresses painfully and slowly from the skin, usually on the lower extremities. The disease can infect animals exhibit sustainable animal cycles in some parts of the world but does not act as human infection reservoirs. The infection has been endemic across the Sahel belt of Africa from Mauritania to Ethiopia but was eliminated from Asia and some African countries [1-4]. This disabling water-borne helminthic disease has been targeted for eradication globally since 1986. People become infected when they drink water, usually from streams or ponds contaminated by copepods (water fleas) which harbor immature forms of the Dracunculus larvae $[5,6]$.

The infected person feels no symptoms while the larvae grow to adult size and reach a length of about one meter within 9-12 months (Fig. 1). The worm then begins to migrate to the superficial layers of the body, causing a blister on the skin through which it emerges. In more than $90 \%$ of cases, the worms emerge through legs or feet, rarely from other parts of the body [7, 8]. Fatalities from the disease are rare and usually result from complications due to secondary infections, but it is debilitating and often leaves victims crippled for life. The disease's worst effects are measured in terms of person-hours of lost labor when many people are incapacitated by the disease [9-11]. The most susceptible victims of the disease live in remote rural areas that lack potable water. The incidence of Dracunculiasis is thus directly linked to the lack of access to safe water. No effective chemotherapy or vaccine for the disease is available, and infected people do not become immune to future infections by the parasite. However, Dracunculiasis is preventable and was targeted for eradication [2, 12].

When the Carter Center began leading the Guinea Worm eradication campaign in 1986, there were an estimated 3.5 million disease cases in 20 countries in Africa and Asia. The number of reported cases reduced 
Bimi et al.

by more than $99.5 \%$ to 16,026 by 2004 . Therefore, Guinea Worm was poised to be the next infection following smallpox to be eradicated from the world and the first without a vaccine or treatment [6, 13]. The Guinea Worm Eradication Program (GWEP), established in 1986 under the Carter Center's Global 2000 Program, sought to rid future generations of affliction by 2005 . This multilateral partnership brought together organizations like the World Health Organization (WHO), United Nations International Children's Emergency Fund (UNICEF), Centers for Disease Control and Prevention (CDC) of the United States, and the World Bank as well as national governments and the pharmaceutical industries in a program combining eradication efforts, training, and research [6, 14].

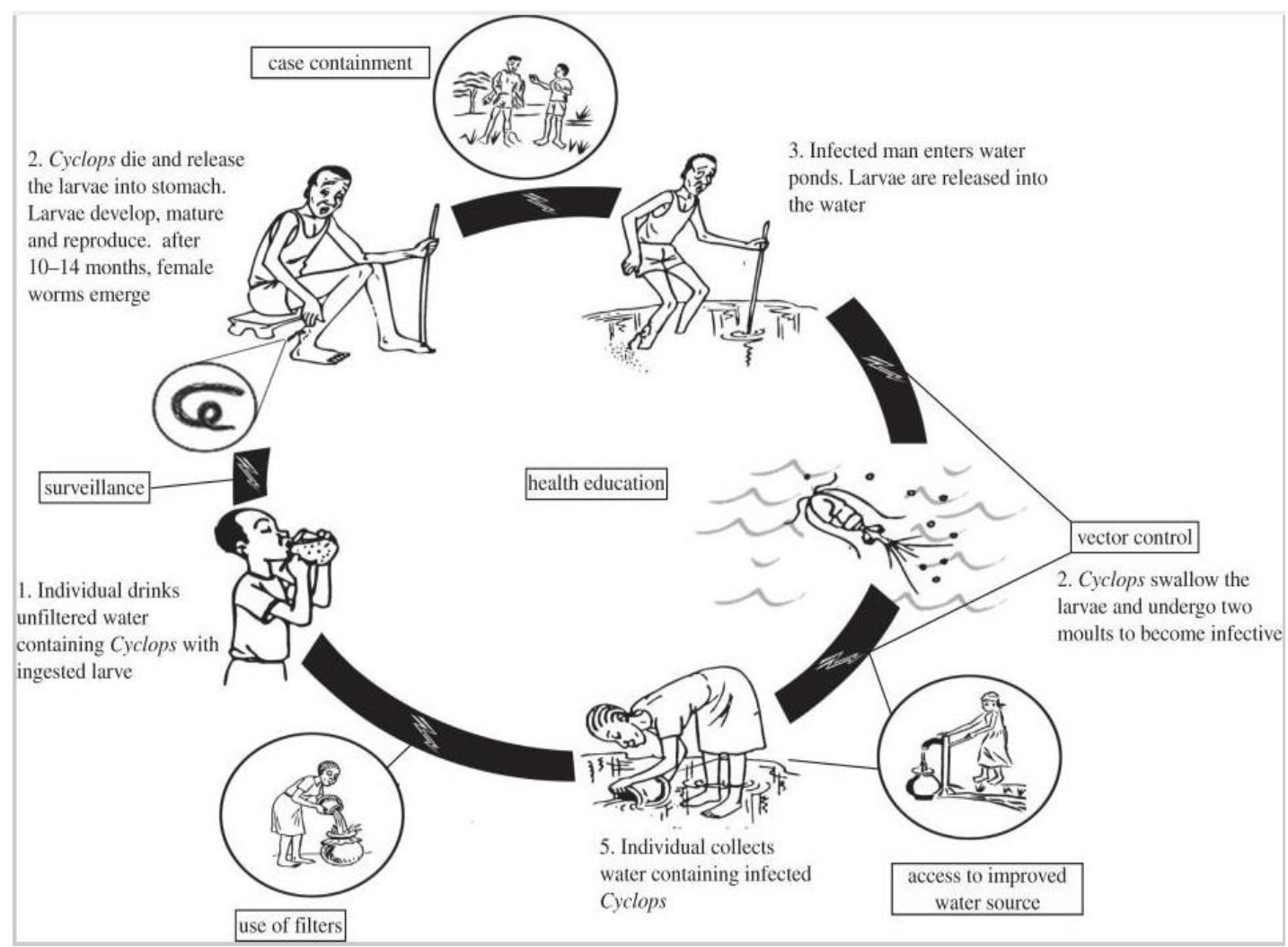

Fig. 1. Guinea worm life cycle and interventions to interrupt transmission [21].

At the Guinea Worm Eradication Program commencement, Ghana and Pakistan were the first nations to receive assistance to eliminate the disease. The Carter Center's relationship with Ghana's Ministry of Health has remained strong as the international eradication campaign has grown to include other partners like the CDC, WHO, and UNICEF [15, 16]. As of 2010, Ghana was the fourth most endemic country globally, accounting for less than $1 \%$ of worldwide cases. Since work commenced, Ghana has reduced its reported cases of Guinea worm disease from 180,000 in 1989 (Fig. 2) [22] to eight cases in 2010 (Fig. 3) [23], the fewest number of cases ever reported since the inception of the program $[17,18]$.

When the Ghana Guinea Worm Eradication Program (GWEP) was first launched in 1987, coordinators were appointed in every region with responsibilities that included, among others, (i) health education, (ii) distribution of nylon filters and pipe cloth filters, (iii) Abate/Temephos application, (iv) training of village volunteers for effective case management, (v) worm removal by surgery, (vi) direct advocacy through nongovernmental organizations in the water and sanitation sector to provide safe drinking water, and (vii) active surveillance. In the districts, initiatives included film shows on the transmission cycle of the Guinea Worm, filter inspection, distribution and replacement of filters, monthly meetings with community-based surveillance volunteers, and involvement of Red Cross women who serve as peer educators on the core eradication strategies $[19,20]$.

\section{METHODS}

This article employed a literature search and review/analysis of program documents, technical and non-technical reports, public statements, and research documents. Besides, additional research was conducted through personal contacts, interviews, and discussions with some key people who had good knowledge of the program and those directly responsible for implementing the GWEP in Ghana. However, it should be noted that the documentation is by no means comprehensive, even 
though the information obtained is extensive enough to enable valid conclusions. It was also anticipated that since there was a lack of documentation available for review, especially within Ghana, the quasi-systematic review approach was appropriate.

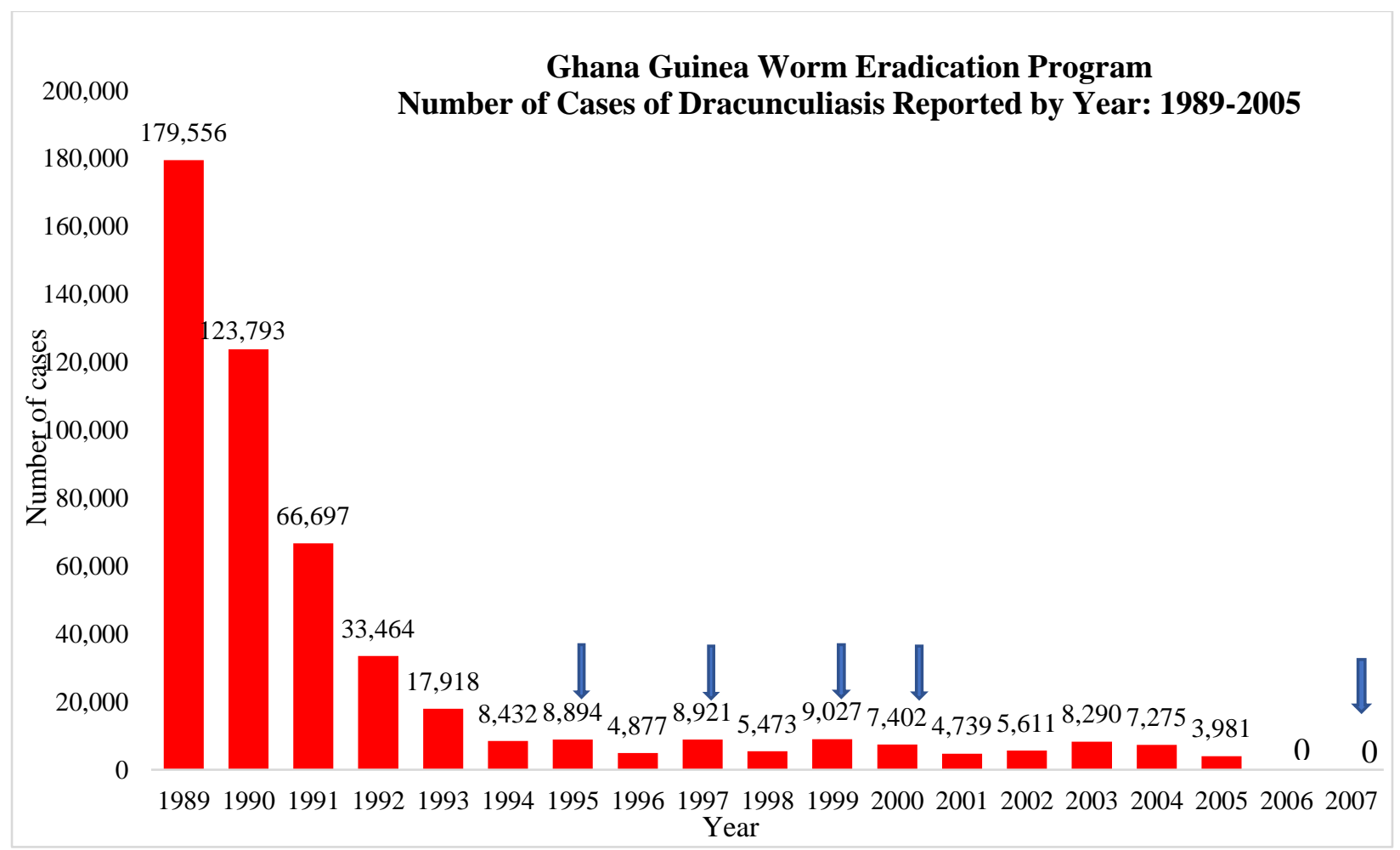

Fig. 2. Number of reported cases of the Guinea Worm Disease over 17 years in Ghana. Extracted from the national case search, Department of Public Health Service, Centers for Disease Control and Prevention [22].

\section{FINDINGS}

The global Dracunculiasis Eradication Program spearheaded by President Jimmy Carter and the Carter Center has quietly crept towards world eradication with stunning success (Fig. 2) [22]. Indeed, Ghana was on the verge of eradicating the disease, with no active cases reported in the country since May 2010. This success story is due to health education and low-technology measures that promote behavioral change. These include preventing people with emerging worms from entering drinking water sources, constructing boreholes/deep wells, treating water with Abate larvicide, and promoting boiling or filtration of drinking water.

This review has revealed that since its inception in 1987, Ghana's Guinea Worm Eradication campaign had made resounding progress, with the country reducing its cases of Guinea Worm Disease from 180,000 in 1987 to 8,432 in 1994 (Fig. 2) [22]. However, a review of existing data and personal interactions with the program eradication secretariat personnel indicates that Ghana's program appeared to have suffered a decade of disappointing stagnation following disruptive ethnic conflicts in its most disease-endemic areas in 1994. However, by 2002 Ghana was second only to Sudan in the reported number of Dracunculiasis cases, with the Northern Region accounting for $76 \%$ of all cases.

From January to June 2003, there were 5,416 reported cases in Ghana, an increase of $74 \%$ compared to the same period in 2002, attributable to improved surveillance by village-based volunteers of the community-based surveillance system during the preceding 12 months. Local records in the districts revealed that since early 2002 , more than 6,500 members of the Ghana Red Cross Society Mothers' Clubs were mobilized to help conduct surveillance for cases and health education in disease-endemic villages, thus supplementing the efforts of existing village volunteers. Support from these women volunteers contributed to an increase in coverage of large guinea worm-endemic villages. During the last half of 2004, Ghana achieved a $44 \%$ reduction in cases compared to 2003 . There was a reduction of 59\% during the first three months of 2005 compared to the same period in 2004. This reduction is undoubtedly evidence of the remarkable contributions of these volunteers. In 2005, the national program reported a decrease of $45 \%$ in reported cases (from 7,268 cases in 2004 to 3,977 in 2005). However, Ghana still ranked second after Sudan as the country with the most cases, reporting $37 \%$ of the global total in 2005 . The Northern 
Bimi et al.

Region continued to report the majority of cases (75\%; 2,981 of 3,981 cases), followed by Upper West Region (8\%), Brong Ahafo Region (7\%), and Volta Region (286 of 398 cases).

In 2006, Ghana reported 4,136 cases (including two imported cases from Mali) from 606 villages, an increase of $4 \%$ compared to 3,981 cases (including four imported cases) reported in 2005. The country, however, still ranked second only to Sudan in the number of reported cases. Still, it is gratifying to note that $75 \%$ of all cases reported in Ghana were contained, with no new cases reported (Fig. 2) [22]. The records further revealed that most cases (89\%) were from the Northern Region, 204 cases $(5 \%)$ from the Brong-Ahafo Region, and the remaining 6\% from the Upper West and Volta Regions. We also noted that most cases reported in 2006 were from 316 villages that also reported cases in 2005, indicating that these villages retained the potential to transmit the disease. Peak transmission occurred during the second half of one year and the first half of the following year, with the highest recorded in December and January. This narrative shows the performance or non-performance of the Ghana Guinea Worm Eradication Program since the 1980s. In 2010, the remaining cases of Dracunculiasis worldwide were reported in four African countries, namely Sudan (1,698), Mali (57), Ethiopia (20), and Ghana (8).

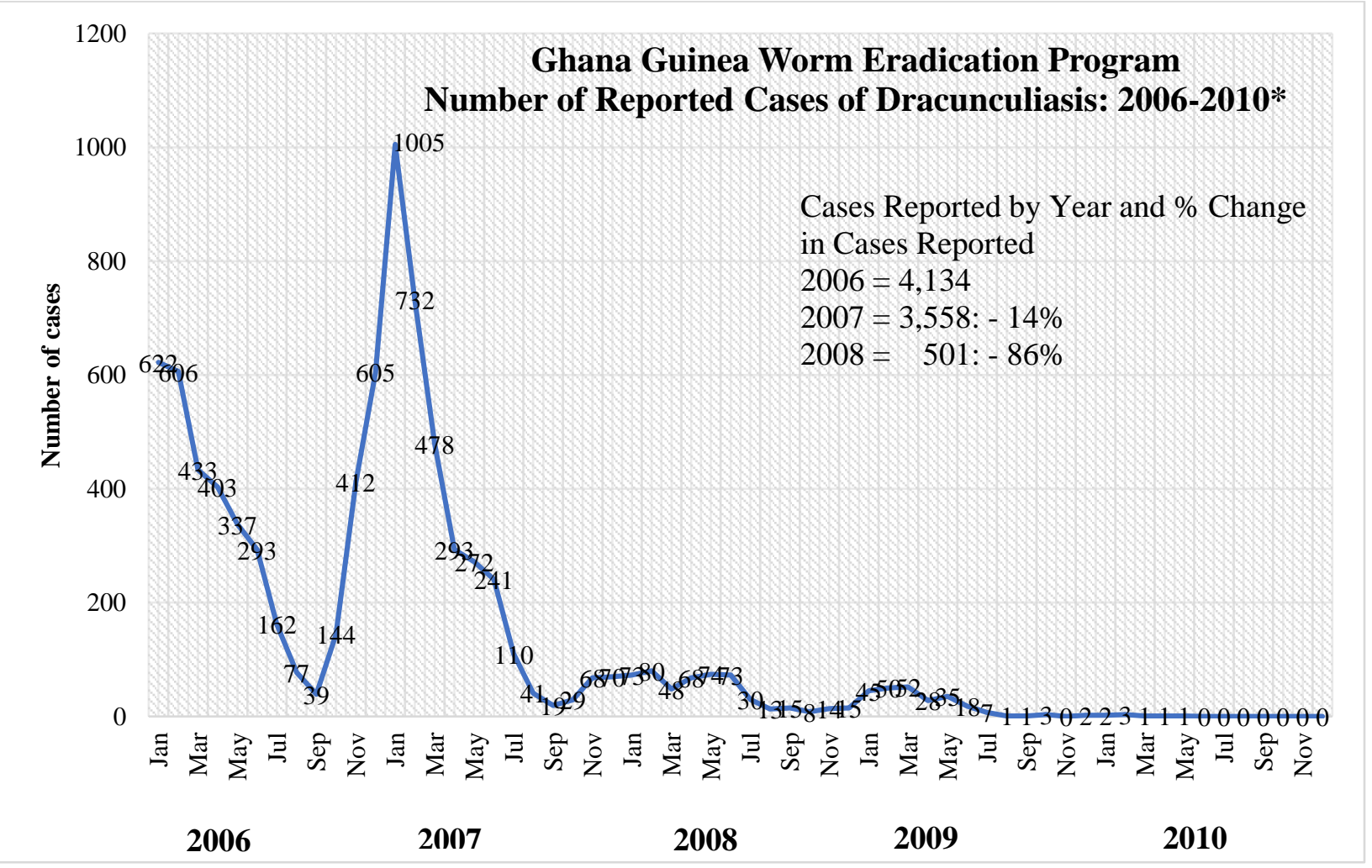

Fig. 3. Number of reported cases of the Guinea Worm Disease over five years. Extracted from the Department of Public Health Service, Centers for Disease Control and Prevention [23].

With these laudable achievements, it is pertinent to review Ghana's performance in the global Guinea Worm Eradication race. As of 1997, Ghana was in the third position globally with the most significant number of Guinea Worm cases after Nigeria and Sudan. By June 2003 , the country had risen to the second position after Sudan, and in 2004 earned the unenviable position of the country with the highest number of Guinea Worm cases globally (nine cases more than Sudan). The country had bounced back to the last but one position since 2005, despite the massive investments and interventions to sustain the program.

\section{DISCUSSION}

How Ghana Freed Itself from the Guinea Worm Disease. The country made remarkable progress in the eradication effort in the 1990s after Ghana's President spent 21 days in the most endemic Northern Region sensitizing indigenes on the disease. Unfortunately, however, Ghana rose to become the world's most endemic country in 2004 with a total of 7,275 reported cases of Guinea Worm. However, by the following year, the country had become the second most endemic country globally, accounting for approximately $37 \%$ of cases worldwide and $79 \%$ of cases outside Sudan. Since the first launch of the Ghana Guinea Worm Eradication 
Program, the country has reduced its cases of Guinea Worm Disease from 180,000 in 1987 to 8,432 in 1994 (Fig. 2) [22]. The Ghana Guinea Worm Eradication campaign was making progress until 1994, when project funding was exhausted. Unfortunately, this coincided with an escalation of an ethnic conflict in the most endemic northern region. The program, therefore, stagnated for nearly ten years before revamped in 2000. Increases in cases after that era were due to better surveillance (case detection) following its revamping.

One thus begins to wonder what steps were taken differently to achieve better results. However, it was ascertained that the interventions/strategies initiated earlier were not working as expected, apart from some "socio-politico-economic" and technical problems and misapplication of specific eradication strategies. Below are factors considered as having contributed to relapses and the relatively numerous re-launchings of the eradication program.

Tribal Conflict and Political Instability. One of the principal reasons for the Ghana Guinea Worm Eradication Program's stalled progress has been the political instability and ethnic conflicts in northern Ghana, which started in the early 1990s. While not wholly blaming the shortcomings or failures on these political problems, it is true that the ethnic conflicts in the eastern part of the Northern region (then the most endemic area in Ghana) disrupted health efforts and created program instability as well as safety concerns. First, migration of the Nanumba, Konkomba, and Dagomba ethnic groups, due to the ethnic conflicts, often required the program to adopt alternative approaches to Guinea Worm health education such as targeted radio messages, continued community volunteer recruitment, and the development of additional educational materials. Secondly, because these migrating groups rarely fetched water from the same permanent water sources, it was not enough to dig a well or conduct health education sessions at local schools

Safe Water Supply. According to Steve Becknell, Technical Assistant of the Ghana Guinea Worm Eradication Program in Ghana's northern Sector, "availability of safe drinking water in all endemic communities remains the single most effective solution for eradicating the disease." Indeed, in the early discussion of strategies for eradicating Dracunculiasis, the provision of safe water was generally seen as the intervention of choice. However, water supplies are built and maintained for many other reasons besides preventing Guinea Worm Disease. This eradication goal was initially proposed as a target for the International Water Decade. Early eradication efforts in Nigeria and Benin through the investment of significant parts of these countries' budgets in water supply construction showed evidence of the positive impact of water supplies on Dracunculiasis. However, an investigation of the reasons for the failure of this initiative in Ghana revealed several constraints. In a then heavily indebted developing country like Ghana, where rural water supply is capital-intensive, the cost of drilling boreholes was quite deterrent (US\$ 10,000 for one borehole). As the Director of Ghana's Guinea Worm Eradication Program (GGWEP) stated, "the provision of safe water is painfully slow and lags behind other guinea worm eradication interventions." To support Guinea worm eradication, the GGWEP suggested that global partners like the WHO, UNDP, UNICEF, and Global 2000 should provide funding to assist the Government of Ghana in providing boreholes in endemic communities and rehabilitating broken-down wells. Continued international and local political commitment is critical for the success of the guinea worm eradication effort.

Many water systems in Africa have fallen into disuse within a few years of construction because of a lack of proper maintenance. In some cases, the resulting reversion of the people to unprotected water sources has resulted in the disease persisting or developing in epidemic form in peri-urban settings [4]. This narrative was the experience in La Cote d'Ivoire and, to some extent, Ghana, which has similar problems with the culture of non-maintenance. A functioning water supply system will still be ineffective if it is not accessed, especially when it is not close to residential areas. In endemic countries such as Ghana, a hand pump may be the only water source kilometers away in the dry season. Guinea worm transmission peaks during the rains, when people are often infected from the many ephemeral ponds within a few hundred meters from their houses. It is worth noting that all-year-round water availability may not guarantee the elimination of Dracunculiasis if the local people do not understand the transmission dynamics of the disease.

Guinea worm infection is often acquired through the incautious use of unprotected water sources when people are away from home, especially when working in the fields. People's economic activities (young men, farmers, and cattle herders) from the currently endemic areas also expose them to an increased risk of getting infected and developing the disease. The risk is higher because they are often away for weeks from the community base where household filtered water should be available and often drink from numerous unprotected water sources in the field. The common observational evidence in most endemic villages in Ghana is that adults, particularly farmers, are more commonly infected than children are.

Filtration of Drinking Water. The filtration process may be easy but often not used by people because of socio-cultural and technical reasons. For thousands of poverty-stricken and mostly illiterate villagers living in remote and usually inaccessible communities with diverse dialects, achieving such behavioral change is a significant challenge. Stories are told of the disappointment of implementers of early eradication programs when distributed filters (cotton cloth) were sometimes used as clothing or for decoration. There is 
Bimi et al.

also the common complaint that the filter soon clogs up and makes the filtering process more difficult and timeconsuming. Even introducing a better-quality monofilament nylon filter cloth in the early 1990s did not improve the situation, with people using them to sew wedding gowns. In 2005, approximately 144,000 new pipe filters were distributed to every eligible person (more than five years old) in Ghana's seven most endemic districts, although some people might have failed to use them or used torn or defective ones.

Water treatment with Abate. Apart from the above challenges, there have been technical problems regarding the application of the Abate ${ }^{\circledR}$ larvicide, which is recommended only when the case investigation revealed that the imported case(s) contaminated sources of drinking water. There is then a 10-day window of time to apply the Abate ${ }^{\circledR}$ and prevent any secondary transmission. The lack of technical know-how for applying the chemical has often led to wrong dosing or misapplication problems. For instance, appreciating the geometry of the waterbody to calculate the required concentration of Abate ${ }^{\circledR}$ has always been a challenge to predominantly illiterate communities. When the treatment is not fully effective, there is an increased risk of the cyclops developing resistance to the cyclopicide. Even when treatment successfully removes the pond cyclops, there is a re-population period of five weeks because the chemical only kills the adult stages of the crustacean. Also, applying Abate to domestic water sources alone may not permanently eliminate guinea worm disease as other contaminated water sources are accessed.

Case Management and Containment. Avicenna (980 - 1037) first recommended surgical removal of the worm, and traditional healers practiced it in Iran and in what is now Uzbekistan. Great skill is required to avoid tearing the worm, which entangles around joints or tendons. Removal before emergence avoids the pain and suffering caused as the worm emerges and contains the case by preventing contamination of water sources. Ghana is the only African country to include this intervention in its Dracunculiasis eradication program but abandoned it in early 2000. Some unscrupulous health workers abused the reward system introduced for worms removed. Some health workers were charging fees for the service that was supposed to be free and sometimes cut the removed worm into pieces to claim multiple rewards for the same worm. The early intervention in the program meant there were too many cases to contend with and costs were too high.

The practical implementation of case containment required that each case be reported to the supervisor or the village health worker within seven days. The supervisor then pays a diagnosis verification visit to ensure that all necessary measures are taken. However, since those who ensure the reporting of cases are volunteers, there has been no commitment to guarantee that the rightful things are done. There is also the challenge of a lack of funding to execute the program.

Health Education and Prevention of Patients' Contact with Ponds. Health education has been the intervention that has had the most significant impact in Ghana and the world. This intervention involved promoting cloth filters to remove cyclops from drinking water and prevent the contamination of ponds by patients. It has proved much more effective and exceeded the expectations of many health education professionals. For instance, through intensive health education, the eradication program staff in Northern Ghana effectively dealt with their pond-related transmission problems in record time.

Conclusion. This study revealed that Ghana's eradication program ended a decade of disappointing stagnation following the disruptive ethnic conflict in its most disease-endemic area in the early 1990s. Elimination of guinea worm disease led to a boom in the production of staple foodstuff such as yams in the socalled Eastern Corridor. Despite the substantial gains Ghana made in the mid-1980s in her eradication efforts, breaking transmission eluded the country due to some reasons earlier discussed. Continued international and local political commitment, active surveillance, and intensifications of interventions at all levels were some of the reasons that led to our ultimate aspiration of "guinea worm-free" Ghana. This review is undoubtedly vulnerable to some possible inherent biases like inaccessibility to some helpful information that may have been held in several other institutions that did not directly deal with the eradication program in Ghana.

Countries like Southern Sudan, Mali, Chad, Ethiopia, Angola, Cameroon, and Niger, where the Guinea Worm Disease is still endemic (Fig. 4) [24], should learn lessons from the Ghana National Guinea Worm Eradication Program. Among other strategies, the following are recommended: 1) Strengthening surveillance and interventions by improving data collection and validation at the village level through periodic refresher training courses. 2) Regular supervision and increasing the number of village-based volunteers and zonal coordinators where necessary. 3) Increasing the frequency and quality of supervision at all levels. 4) Ensuring active surveillance in communities with low guinea worm incidence or at-risk communities where CBS is not yet in place. 5) Keeping villages that have recently been freed from guinea worm disease under active surveillance for at least three years of zero reporting.

\section{ACKNOWLEDGMENTS}

The authors are very grateful to the National Coordinator of the Ghana Guinea Worm Program and all the contact persons at the District Assemblies.

\section{CONFLICT OF INTEREST}


The authors declare no potential conflict of interest associated with this work.

\section{REFERENCES}

1. Muller R. Dracunculus and dracunculiasis. Adv Parasitol. 1971; 9: 73-151.

2. Muller R. Guinea worm disease: epidemiology, control, and treatment. Bull World Health Organ. 1979; 57 (5): 683-9.

3. Watts SJ. Population mobility and disease transmission: the example of guinea worm. Soc Sci Med. 1987; 25 (10): 107381.

4. Cairncross S, Muller R, Zagaria N. Dracunculiasis (Guinea worm disease) and the eradication initiative. Clin Microbiol Rev. 2002; 15 (2): 223-46.

5. Ruiz-Tiben E, Hopkins DR. Dracunculiasis (Guinea worm disease) eradication. Adv Parasitol. 2006; 61: 275-309.

6. Hopkins DR, Ruiz-Tiben E, Ruebush TK. Dracunculiasis eradication: almost a reality. Am J Trop Med Hyg. 1997; 57 (3): 252-9.

7. Bierlich B. Notions and treatment of guinea worm in northern Ghana. Soc Sci Med. 1995; 41 (4): 501-9.

8. Boxshall G, Braide E. The freshwater cyclopoid copepods of Nigeria, with an illustrated key to all species. Bull Nat Hist Mus, Zool. 1991; 57 (2): 185-212.

9. Ward W, Belcher D, Wurapa F, Pappoe M. Perception and management of guinea worm disease among Ghanaian villagers. A framework for differential health education planning. Trop Geogr Med. 1979; 31 (1): 155-64.

10. Nwosu A, Ifezulike E, Anya A. Endemic dracontiasis in Anambra State of Nigeria: geographical distribution, clinical features, epidemiology and socio-economic impact of the disease. Ann Trop Med Parasitol. 1982; 76 (2): 187-200.

11. Chippaux J, Banzou A, Agbede K. Social and economic impact of dracunculosis: a longitudinal study carried out in 2 villages in Benin. Bull World Health Organ. 1992; 70 (1): 73 8.

12. Diamenu SK, Nyaku AA. Guinea worm disease-a chance for successful eradication in the Volta Region, Ghana. Soc Sci Med. 1998; 47 (3): 405-10.
Ghana is Free from Guinea Worm

13. Peries H, Cairncross S. Global eradication of Guinea worm. Parasitol Today. 1997; 13 (11): 431-7.

14. Abdou A, editor Proposed WHO/AFRO program for control of dracunculiasis in the African Region. Workshop on Opportunities for Control of Dracunculiasis Contributed Papers ed Schultz, M; 1985.

15. World Health Organization. Evaluation of the dracunculiasis surveillance system in 4 districts in Ghana. Wkly Epidemiol Rec. 2005; 80 (32): 270-6.

16. World Healt Organization. Report on Evaluation of Ghana's Guinea Worm Eradication Program, 6-20 June 2005; Preliminary Report, mimeo. WHO, Geneva. 2005.

17. World Health Organization. Dracunculiasis eradicationGlobal surveillance summary, 2009. Wkly Epidemiol Rec. 2010; 85 (19): 166-76.

18. Cairncross S, Tayeh A, Korkor AS. Why is dracunculiasis eradication taking so long? Trends Parasitol. 2012; 28 (6): 22530.

19. Tayeh A, Cairncross S, Maude GH. The impact of health education to promote cloth filters on dracunculiasis prevalence in the northern region, Ghana. Soc Sci Med. 1996; 43 (8): 1205-11.

20. Cairncross S, Anemana S, Olsen A. Towards the Eradication of Guinea Worm: A Danish-Ghanaian Collaboration. Parasitol Today. 1999; 15 (4): 127-9.

21. World Health Organization. Guinea worm disease: tutor's guide for the training of village volunteers in Southern Sudan. World Health Organization; 2000.

22. cdc.gov [internet]. Department of Public Health Service, Centers for Disease Control and Prevention. Guinea Worm Wrap-up \#162 2006 [Available from: https://stacks.cdc.gov/view/cdc/30443/cdc_30443_DS1.pdf.

23. cartercenter.org [internet]. Department of Public Health Service, Centers for Disease Control and Prevention. Guinea Worm Wrap-up \#202 2011 [Available from: https://www.cartercenter.org/resources/pdfs/news/health_publi cations/guinea_worm/wrap-up/202.pdf.

24. cdc.gov [internet]. Department of Health and Human Services. WHO Collaborating Center for Dracunculiasis. Guinea Worm Wrap-up \#273. [Available from: https://www.cdc.gov/parasites/guineaworm/resources/pdf/273. pdf.

\section{Cite this article:}

Bimi L, Anto F, Tetteh AK. Ghana is Free from the Guinea Worm after a 33-Year Eradication Program. J Med Microbiol Infect Dis, 2021; 9 (2): 55-61. DOI: 10.52547/JoMMID.9.2.55. 